\title{
Evaluating the Anxiety and Adjustment of Physical Education Teachers Implementing Flipped Class Based on Data Visualization Technology
}

\author{
Feilong $\mathrm{Wu}^{1,2}$, Vivian B. Titular ${ }^{2}$, Shipeng Ding ${ }^{3 *}$ \\ ${ }^{1}$ Department of Physcial Education, Xi'an Aeronautical University, Xi'an, 710000, Shaanxi, China \\ ${ }^{2}$ Graduate School, Jose Rizal University, Manila Philippines, 0900 \\ ${ }^{3}$ Teacher Education College, Lishui University, Lishui, 323000, Zhejiang, China \\ *Corresponding author.
}

\begin{abstract}
:
Data visualization technology uses graphics and images to intuitively express the influence of teachers' implementation of flipped physical education. The sample comes from a flipped physical education classroom conducted by 130 physical education teachers $(\mathrm{N}=130$, age 28-55) from 6 university sports departments in China. The research results show that gender, teaching age, and education level have a greater impact on teachers' implementation of flipped physical education classes, and there are significant differences in anxiety levels. During the COVID-19 period, how to implement physical education has caused a lot of troubles and concerns. Teachers generally believed that they had lost their status as physical education teachers, and very worried about how toimplement physical education In quarantine state. However, after a period of trying to flip physical education, teachers' attitudes have changed significantly. Most physical education teachers hold a positive attitude. This is because their worries and confusion about flipping the physical education classroom transition to knowing the reason, and increasing the awareness and initiative of physical education teachers in teaching.
\end{abstract}

Keywords: Data visualization technology, Flipped physical education classroom, Physical education teacher, Anxiety, quarantine state, Positive attitude.

\section{INTRODUCTION}

According to the latest real-time statistics of the World Health Organization, as of August 14, 2021, 43,33094 people worldwide have died of new coronavirus pneumonia, and 
Article History: Received: 28 October 2021 Revised: 05 December 2021 Accepted: 10 January 2022 Publication: 28 February 2022

205,338,159 confirmed cases(Last update: 14 August 2021, 00:47 am GMT+8)[1]. This crisis has spread globally, reducing the spread of the new crown pneumonia virus, requiring citizens to stay at home and shutting down various business departments, alleviating the humanitarian security crisis, protecting the lives and health of global citizens, and maintaining social distancing is considered to be the most effective prevention strategy [2,3]. Due to the spread of COVID-19, 1.5 billion students in 190 countries and regions around the world cannot attend classes normally. Educational institutions have switched from traditional teaching methods to remote teaching in a relatively short period of time, and teaching methods have undergone fundamental changes [4]. During the epidemic, the application of digital technology in the field of education promoted the digital transformation of education and provided students with a large number of online teaching resources. Interactive technology promotes the innovation of higher education methods, which helps to promote collaboration, inquiry and effective interactive communication in the online learning environment. It is in this context that teaching method of "students as the main body, teachers as the leading role, emotion as the main line" has made new breakthroughs in the field of education. Technology-driven models, such as the flipped classroom (FC), which provides students with direct access to video lectures, slides, and other teaching resources on online educational platforms, have gradually gained visibility and relevance [5].This interactive communication-oriented teaching method quickly establishes independent learning ability. Physical education teachers obtain feedback and help through innovative teaching resources and relational virtual learning space management system, and solve and replace face-to-face effective of "teaching and learning". However, due to the particularity of physical education, this teaching mode generally increases the psychological pressure and negative emotions of physical education teachers and students, and creates anxiety. Therefore, some physical education teachers admit that their digital literacy is not enough to cope with the regular online teaching activities during the pandemic [6]. Cevikbas (2020) pointed out that effective flipped teaching is closely related to the specific subject content required. Get videos, slides, infographics and other learning resources through online platforms [7]. Islam (2020) pointed out that with regard to the challenges associated with teachers during COVID-19, they believe that signs of anxiety and depressive symptoms of teachers are rapidly increasing under special conditions when they are not proficient in digital technology [8]. When preparing teaching materials and providing learning guidance in asynchronous courses, the influence of spatial distance may cause psychological distress [9]. For physical education teachers, so, flipping the physical education classroom not only increases the workload of physical education teachers, but also faces the psychological pressure brought by the severe epidemic. Especially the older physical education teachers are very unfamiliar with the application of digital technology in the field of physical education. Therefore, it is necessary that how to alleviate the anxiety of teachers in the flipped physical education classroom, for further discuss and reflect, so as to improve teachers' worries and adjust teaching methods so 
Article History: Received: 28 October 2021 Revised: 05 December 2021 Accepted: 10 January 2022 Publication: 28 February 2022

that teachers can master what they have teach as soon as possible.

\section{METHODOLOGY}

\subsection{Basic Characteristics of Participants}

In this study, the respondents are all university physical education teachers, the sample age is between 28-55 years old $(\mathrm{M}=2.52, \mathrm{SD}=0.98)$, most of the respondents are male (76 males (58.5\%) and 54 Female (41.5)). Respondents' teaching age is $1-20$ years (including 20 years or more) $(\mathrm{M}=2.38, \mathrm{SD}=1.10)$, and the respondents' education level is between bachelor-doctoral degree $(M=2.09, \mathrm{SD}=0.62)$.

\subsection{Scoring Criteria and Data Collection}

The study used the Spitzer (2006) GAD-7 scale and the Likert five-level scale to assess the anxiety level and attitudes of physical education teachers from 6 universities in Xi'an, China during the 19-COVID pandemic when they implemented flipped physical education courses. The GAD-7 scale consists of 7 items. The anxiety level is calculated from the total score obtained by the individual. A score of 0 to 4 is considered as "no" anxiety symptoms; 5 to 9 are considered as "mild" anxiety symptoms A score of 10 to 14 is considered a "moderate" anxiety symptom; a score of 15 and above is considered a "severe" anxiety symptom. The Likert five-level scale consists of 20 items, mainly including 5 parts, which are the ability to master numbers, the effect of teaching methods, the effect of self-driving, the effect of teaching organization, and the effect of teacher feedback. The scoring standard consists of five types of responses: "strongly agree", "agree", "not necessarily", "disagree", and "strongly disagree", which are recorded as 5 to 1 points respectively. The total score of each respondent's attitude is the total score of his answer to each question, this total score can indicate the strength of the attitude of the physical education teacher. After the survey is to obtain informed consent from the physical education teachers complete the form anonymously, recovered directly by e-mail.

Before the investigation, the electronic informed consent form was obtained from the physical education teacher, which complied with the Ethics Committee of the Declaration of Helsinki (No. 202001).

\subsection{Statistical Analysis of Data}

All survey data were entered and checked for invalid values by three research assistants. Cronbach's Alpha reliability analysis was performed on the input data through SPSS20.0 to test 
Article History: Received: 28 October 2021 Revised: 05 December 2021 Accepted: 10 January 2022 Publication: 28 February 2022

whether the composition of the GAD-7 scale and Likert scale is reliable. According to the recommendations of Nunnally (1978), Cranbach's a coefficient is above 0.6, and the benchmark study is above 0.8. In general, Cranbach's a coefficient is above 0.6, which is considered to be more reliable. The overall questionnaire $(\alpha=0.829)$, GAD-7 scale $(\alpha=0.867)$ and Likert scale $(\alpha=0.865)$, the four parts of the Likert scale are the ability to master numbers ( $\alpha=$ $0.641)$, teaching Method effect $(\alpha=0.632)$, self-driven effect $(\alpha=0.624)$, teaching organization effect ( $\alpha=0.667)$, teaching feedback effect ( $\alpha=0.635$ ). In all cross-sections, the GAD-7 scale and Likert scale's Bartlett sphere test reached a significance level of less than or equal to 0.001 , and the KMO was 0.912 and 0.832 , respectively.

\section{RESULTS}

\subsection{Analysis of the Overall Anxiety of Physical Education Teachers}

As shown in Figure 1, according to the calculation standard of GAD-7 scale, the total anxiety of physical education teachers is obtained through descriptive statistical analysis. The flipped sports classrooms implemented by PE teachers during the COVID-19 period are generally mildly anxious $(\mathrm{MSD}=7.833 .72$, Median=7) and moderately anxious (Upper=10). Figure1S is a supplementary explanation of the anxiety level of each physical education teacher. Those with a total score of 15 point or above are severe anxiety, 10 to 14 point are moderate anxiety, and 5 to 9 point are mild anxiety, 0-4 point no anxiety

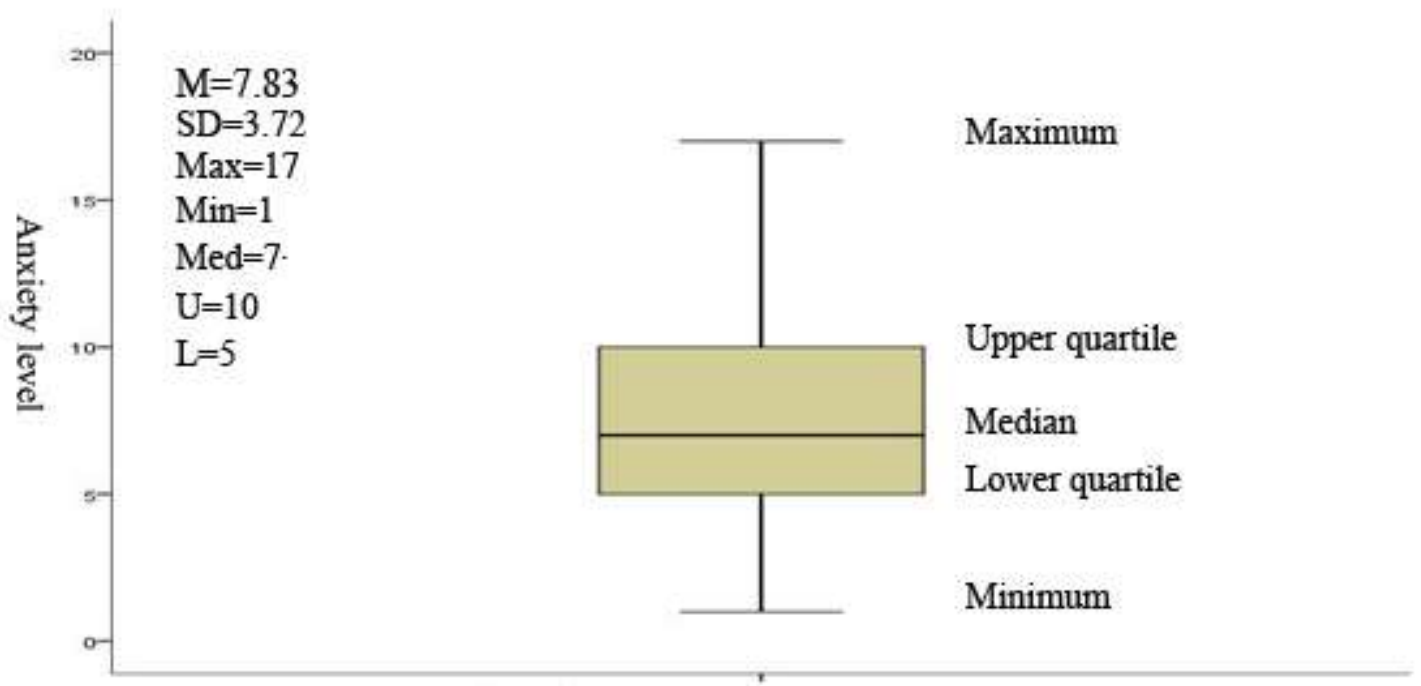

Fig. 1: anxiety total score statistics 


\subsection{Differences in Anxiety Levels}

Figure 2 is divided into 4 indicators to express the difference in the average anxiety level of teachers in the flipped physical education classroom. In item A, the anxiety level of female teachers is generally higher than that of male teachers. In item B, the anxiety level of teachers gradually increases with age. In item $\mathrm{C}$, the education level of teachers is also an important reference indicator that affects anxiety. In item D, teaching age is an important factor that directly affects the individual's anxiety level. Our research found that the longer the teaching age, the higher the anxiety level. On the contrary, the lower the teaching age, the lower the anxiety level. In an interview, we learned that physical education teachers with older teaching ages have great limitations in the application of digital technology. This may be closely related to the ability of teachers to master digital technology, which generally causes a direct internal reason for a higher level of anxiety.
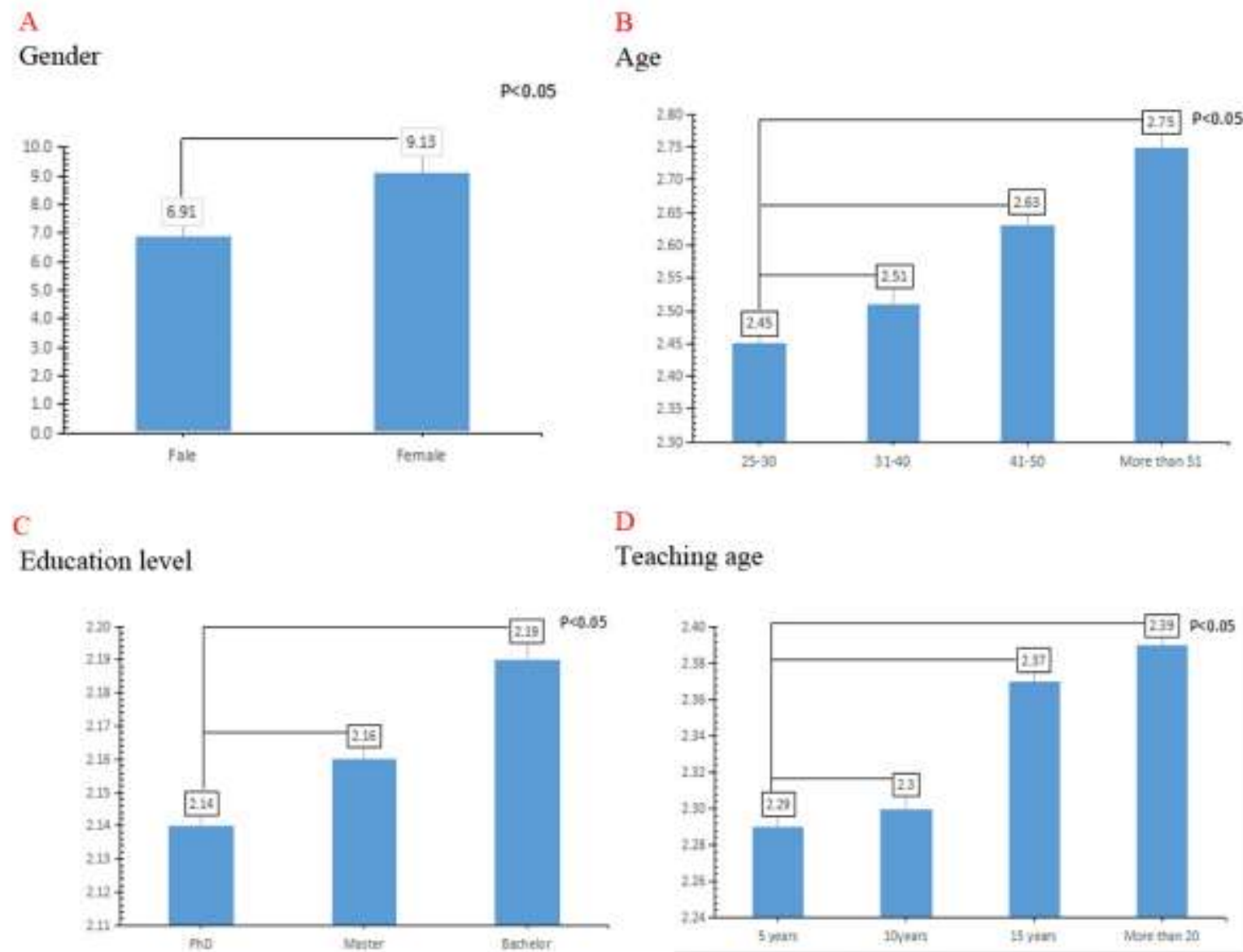

D

Teaching age

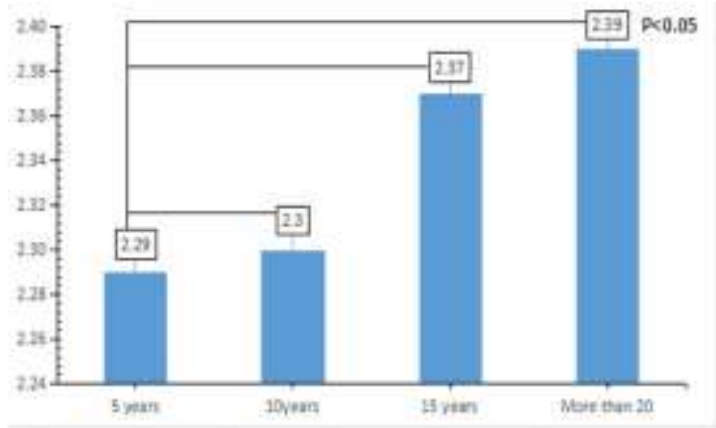

Fig. 2: differences in average anxiety levels 


\subsection{Comparative Analysis of Anxiety Level of Physical Education Teachers}

Figure 3 shows the difference in the anxiety level of teachers in the implementation of flipped physical education classrooms. The A indicator shows that as teachers grow older, the anxiety level of female teachers is significantly higher than that of males. In index B, we found that teachers with higher educational background and older age have the highest anxiety level, among which female teachers are generally higher than men; secondly, female teachers with bachelor degree have higher anxiety level, while male teachers have a stepped anxiety level; and finally The anxiety level of male teachers with a master's degree is inverted $U$ at the age of 28-55 and above, while female teachers are more concentrated except for 46-54. In the C winning bid, we found that doctoral teachers with 10 years of teaching experience have the highest anxiety level (both men and women reach a total score of 15); followed by male teachers with a master's degree of 20 years or more have the highest anxiety level, while women with 5 to 10 years of teaching experience have the highest anxiety level. The anxiety level of teachers is relatively concentrated; finally, female teachers with a bachelor degree of 15 years of teaching experience have the highest anxiety level (total score of 13.5), followed by men. In indicator D, we found that the older the age, the higher the level of education of physical education teachers, the higher the level of anxiety; as the age decreases, the level of anxiety of male doctoral degree teachers is lighter, and male doctors between the ages of 35-45 have no anxiety In contrast, physical education teachers with a master's degree are relatively high, followed by a bachelor's degree. Female master teachers between 28-34 years old are significantly higher than male teachers.

Our investigation and research found that when physical education teachers implement flipped physical education classes, their anxiety level is closely related to gender, age, teaching age and education level. Generally speaking, there are significant differences between female teachers with higher education, older age, and long teaching experience compared with male teachers, and vice versa. 
A

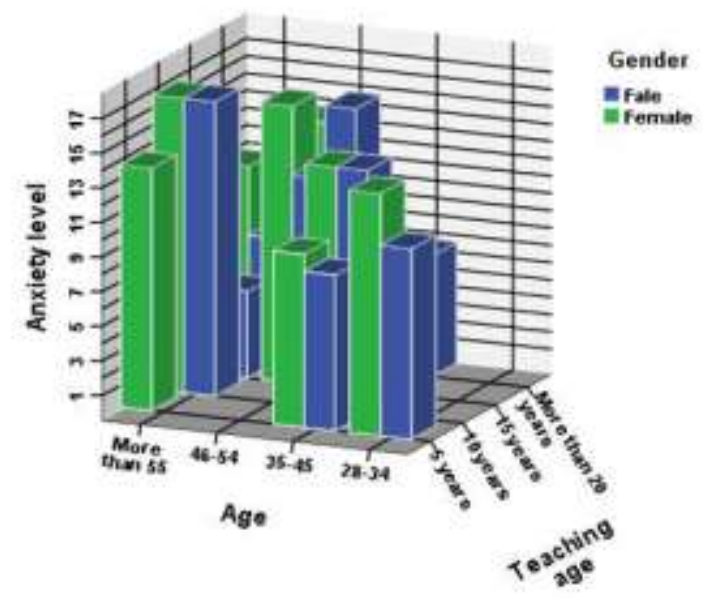

C.

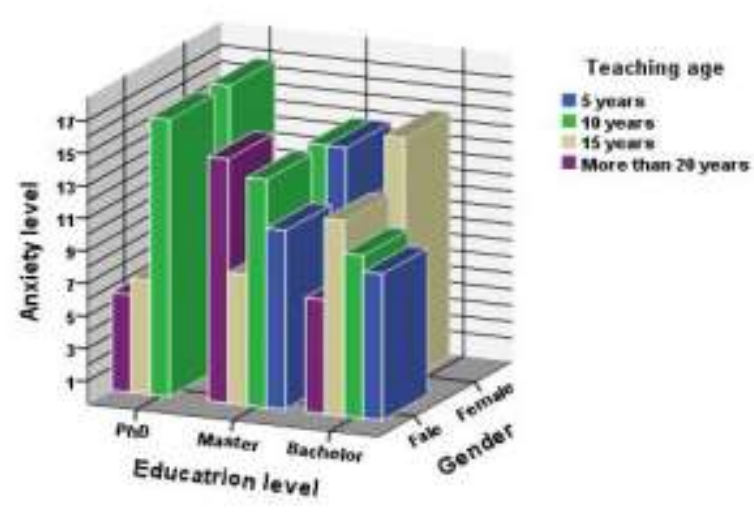

B

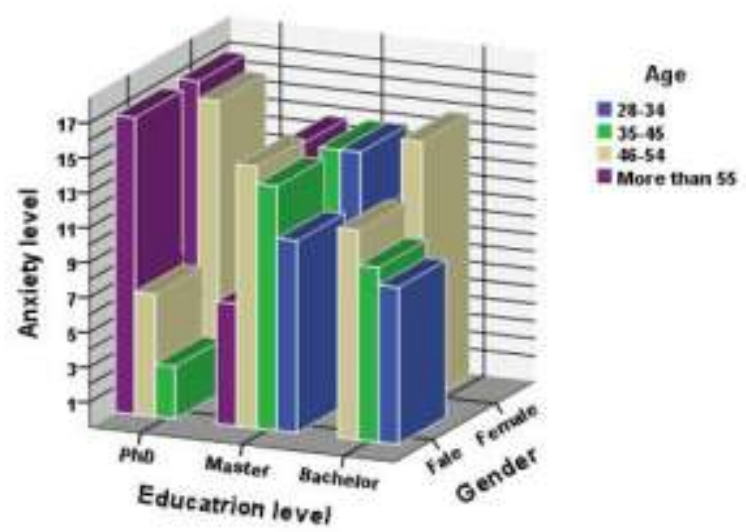

D

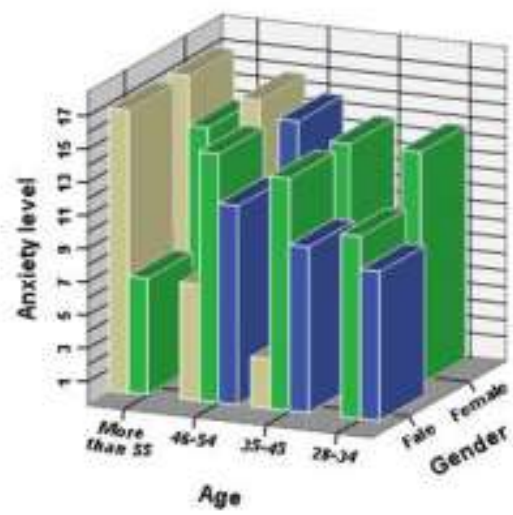

Educatrion level

Eachelor Master

Fig. 3: comparative analysis of the anxiety level of physical education teachers

\subsection{Measures to Adjust the Anxiety of Physical Education Teachers}

How to change the anxiety level of physical education teachers? We conducted a questionnaire survey of 130 physical education teachers. The content of the questionnaire was divided into 5 dimensions. At the same time, according to the calculation standard of Likert scale, how to adjust the anxiety attitude of physical education teachers is evaluated to improve the teaching effect of the flipped physical education classroom. According to Figure 4, the self-driving ability of physical education teachers has reached 4.46 , the change of teaching 
Article History: Received: 28 October 2021 Revised: 05 December 2021 Accepted: 10 January 2022 Publication: 28 February 2022

method is 4.36 , the organizational form of transformation is 4.32 , the improvement of teaching ability is 4.31 , and the feedback of teaching problems is 4.28 . We can find that the overall attitude of physical education teachers is average Above 4.28, physical education teachers unanimously agree that the improvement of the above five abilities can effectively change the anxiety level of teachers.

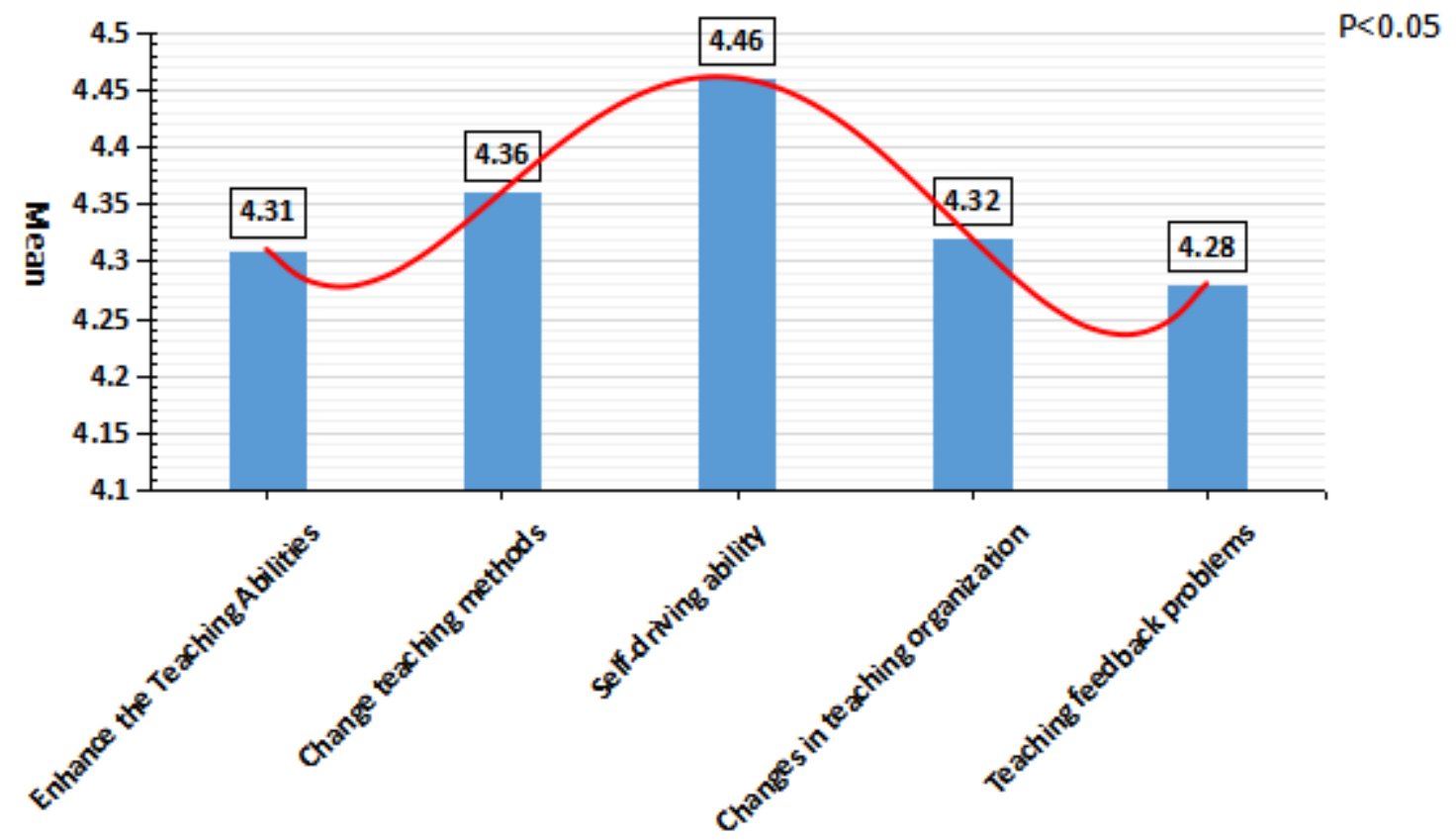

Fig. 4: measures to adjust physical education teachers' anxiety

\section{DISCUSSION}

Our research found that the anxiety of physical education teachers is mainly caused by the first implementation of the flipped physical education classroom. The face-to-face teaching model was deprived during the epidemic, and it is difficult for physical education teachers to learn how to teach physical education through traditional online teaching methods and without isolation. I learned from the interview that physical education teachers generally record courses, and students learn independently or online video to explain teaching and seminars. Facing the new teaching method, the initial physical education teachers felt very incredible, and believed that the implementation of remote teaching in physical education classes was very surprising, so this brought great psychological pressure to the physical education teachers. Berardi (2020) research shows that in the global crisis, the emotions of teachers and students have become more intense and uneasy. Valeria Varea pointed out (Figure 5): Physical education has changed from traditional teaching methods to online physical education. The anxiety of physical 
Article History: Received: 28 October 2021 Revised: 05 December 2021 Accepted: 10 January 2022 Publication: 28 February 2022

education teachers has changed significantly.

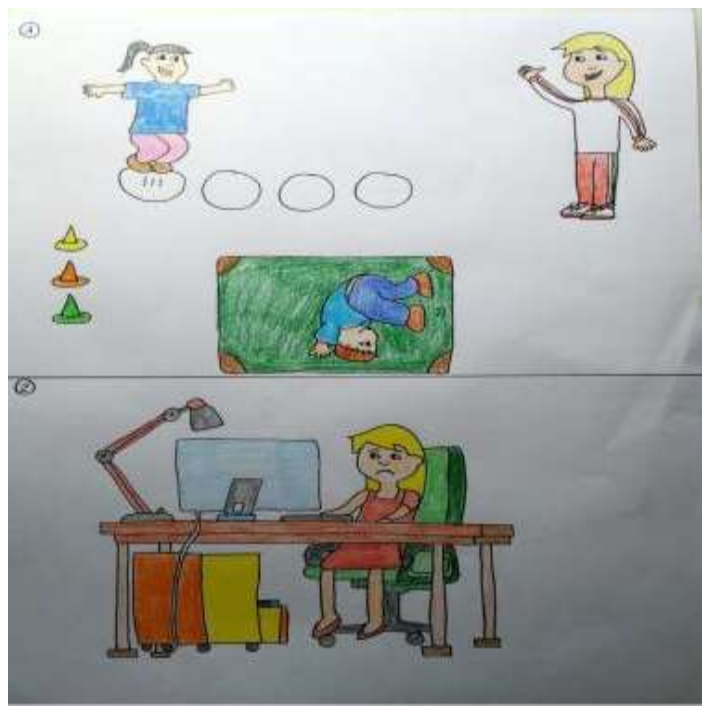

Fig. 5: happy to sad teaching

After an independent sample $\mathrm{T}$ test on the sample, it is found that gender, age, teaching age and education level have a greater impact on the anxiety level of physical education teachers, and the anxiety level of women is significantly higher than that of men. Some female teachers said that during the epidemic, they should not only take care of their families, but also take care of their children's online education issues. At the same time, they must also record physical education videos. A lot of time and energy are all consumed, and the pressure on the heart increases. There are also older physical education teachers who have expressed that they are unacceptable to the new teaching methods. They understand that the application of digital technology by physical education teachers is very scarce, and they don't even know or understand how to apply digital technology to teaching. The teaching methods are obviously different, and the teaching is different (Figure6) [10-13]. Relatively speaking, young physical education teachers are more sensitive to digital technology capabilities and can quickly adapt to digital technology teaching, but they lack the organization of flipped classrooms and have poor teaching experience. In the survey, it was found that the higher the level of education, the higher the level of anxiety of physical education teachers. This is because they have strong physical research. In other words, the teaching theory is very rich, the teaching practice has great defects, and the polarization is more serious. In terms of teaching age, the longer the teaching age, the higher the overall anxiety level of physical education teachers. Although they have rich teaching experience, they have insufficient understanding of information-based teaching equipment and it is difficult to adapt to the new teaching model, especially in the epidemic during the period, I suddenly turned to flipped physical education courses. It is 
Article History: Received: 28 October 2021 Revised: 05 December 2021 Accepted: 10 January 2022 Publication: 28 February 2022

difficult to have sufficient preparation to transition from traditional face-to-face teaching to remote teaching. I am also very worried about whether students can understand and understand physical education teaching videos. Although it has exercised students' independent learning ability to a certain extent, Teachers are generally worried about the effect of offline learning for students. Some teachers indicate that the speed of the Internet of Things is a critical external factor that severely limits physical education.

A

B

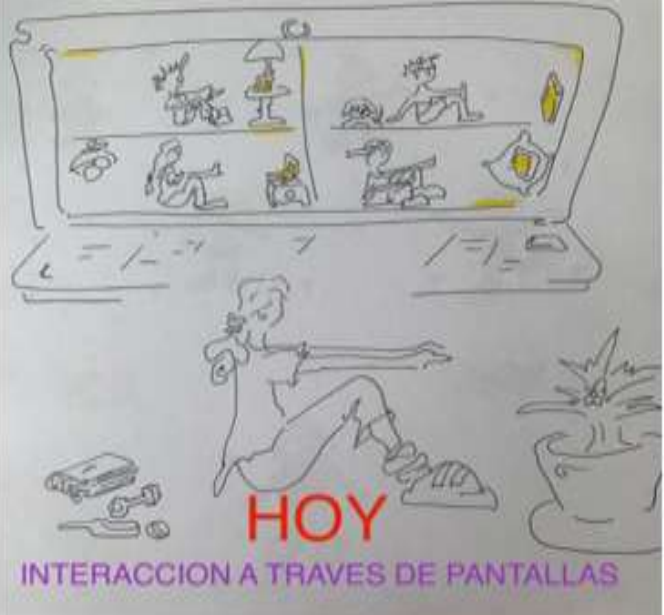

Face to face

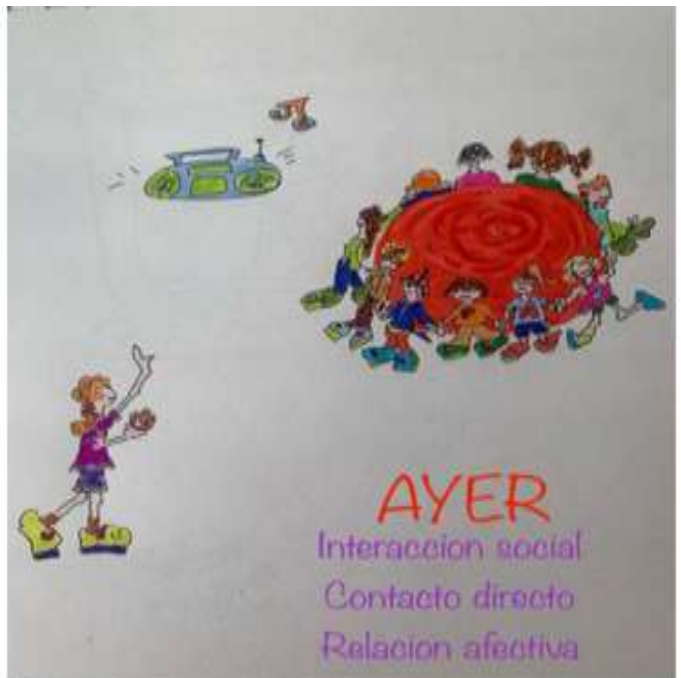

Online seminars and guidance

Fig. 6: comparison of face-to-face teaching and flipped physical education

Through research and feedback, adjusting the anxiety level of physical education teachers lies in self-driving ability, that is, self-adjusting ability and self-adapting ability. Teachers have realized that it is very beneficial to implement flipped physical education during the special period of the epidemic. It not only guarantees the teaching requirements, but also meets the 
Article History: Received: 28 October 2021 Revised: 05 December 2021 Accepted: 10 January 2022 Publication: 28 February 2022

academic requirements of students. It is worth emphasizing that physical education teachers have always believed that changing or innovating teaching methods, transforming teaching organization forms, enhancing teaching skills, personal driving ability and effective teaching feedback, these five dimensions can actively help teachers relieve anxiety. This means that they will explore the innovation of physical education teaching in practice as an opportunity to explore, expand their knowledge and renew their potential as future teachers. Some physical education teachers believe that actively changing the concept of physical education to adapt to the flipped physical education model. This is not only a revolution in teaching technology, but also an innovation in teaching models and teaching methods. Physical education teachers should follow the trend of the times, rather than stagnant, self-enclosed teaching mode.

In this study, we assessed the anxiety level of PE teachers in flipped PE classes during the Covid-19 period. Many physical education teachers emphasize the importance of flipped physical education. Teachers can adjust teaching strategies in time and prepare lessons in advance, instead of blindly instilling "self-centered" teaching and ignoring students' physical learning experience. Therefore, based on the results of this research, the research team recommends that, first, education units should strengthen support for informatization teaching training of physical education teachers, and strengthen the ability of physical education teachers in informatization teaching (such as video production and editing, informatization teaching management, etc.). In this way, physical education teachers can easily control and operate the information technology system. Second, education units should strengthen the psychological guidance of physical education teachers, pay sufficient attention to teachers, and establish teacher psychological counseling workstations to help physical education teachers conduct psychological counseling and adjustments, and alleviate physical education teachers' work, life and other factors. Psychological burden. The third is to change the original teaching evaluation and focus on developmental evaluation, so as to highlight the function of motivation and regulation of evaluation, stimulate its internal development motivation, promote its continuous progress, and realize its own value. The fourth is to change the teaching concept of physical education teachers and form a reverse teaching thinking. Physical education teachers form a teaching concept based on knowledge and technology transfer. With the transformation of society's demand for talents and the transformation of teaching concepts, teachers need to transform into a value-building, the teaching concept of trinity of knowledge imparting and ability training is to guide teaching practice. The fifth is to encourage physical education teachers to explore modern informatization teaching models and improve their mixed and flexible teaching and learning capabilities. The sixth is to provide teachers with sufficient hardware support to ensure the smooth development of remote teaching. Seventh, the use of incentive measures to carry out information-based teaching skills competitions for physical education teachers, so that physical education teachers observe and learn from each other, make 
Article History: Received: 28 October 2021 Revised: 05 December 2021 Accepted: 10 January 2022 Publication: 28 February 2022

progress together, and improve each other, and at the same time promote informationized teaching in the form of informationized physical education competitions.

To sum up, only by strengthening the support of information technology training, changing the concept of physical education teachers, strengthening the psychological guidance of physical education teachers, changing the traditional teaching evaluation, and promoting sports information technology teaching skills competitions, etc., can better ease and Adjust the psychological burden and anxiety level of physical education teachers.

\section{CONCLUSIONS AND LIMITATIONS}

In summary, the research results show that the implementation of flipped sports classrooms during the COVID-19 period has a greater impact on physical education teachers. In particular, the Chinese Ministry of Education has issued an emergency notice that all schools at all levels and types have been suspended, and all courses have shifted to digital teaching. Therefore, under the premise of lack of digital technology training, physical education teachers are very at a loss to implement flipped physical education. They do not know what teaching methods and teaching methods to use to organize physical education. This is undoubtedly difficult for physical education teachers. Posed a greater teaching challenge. Therefore, we research and put forward the following suggestions: (1) Physical education teachers actively explore new teaching methods, change teaching models, improve self-driving ability, and encourage students to participate in the evaluation and feedback of flipped physical education. (2) Physical education teachers should strengthen the training and learning of digital technology. (3) In special periods, physical education teachers should actively explore mixed flexible teaching models to meet the learning needs of different students, so as to ensure the quality of learning. This study still has certain limitations: First, the number of physical education teachers participating in the survey is relatively small. Secondly, although we assessed the internal consistency of the questionnaire (Cronbach's Alpha), there is still a lack of other validity tests. Therefore, more researchers are needed to conduct in-depth research on online sports.

\section{ACKNOWLEDGEMENTS}

The research team is very grateful to all physical education teachers who participated in the survey, and thanks to Dr. Jiang Juan, Dr. Elisa S. Baccay and Dr. Vivian B. Titular for their help and guidance. Thanks to the members of the research team for their assistance to effectively complete this research. Thanks to Dr. Aslan. Bora from Jose Rizal University, Dr. Meng Li from Universiti Putra Malaysia and Dr. Ye Cheng from Dankook University for distributing the questionnaire and collecting statistics 
Article History: Received: 28 October 2021 Revised: 05 December 2021 Accepted: 10 January 2022 Publication: 28 February 2022

\section{REFERENCES}

[1] World Health Organization, August 2021 https://www.who.int/emergencies/diseases/novel-coronavirus-2019

[2] Kien L, My N (2021) The psychological consequences of COVID-19 lockdowns. International Review of Applied Economics 35(2): 147-163

[3] Del Rio, C, Malani P.N (2020) Novel coronavirus-important information for clinicians. JAMA 323: $1039-1040$

[4] Sofianidis A, Meletiou-Mavrotheris M, Konstantinou, P, Stylianidou, N, Katzis, K (2021) Let Students Talk about Emergency Remote Teaching Experience: Secondary Students' Perceptions on Their Experience during the COVID-19 Pandemic. Educ Sci 11: 268

[5] Bergmann J, Sams A (2012) Flip your classroom: reach every student in every class every day. International Society for Technology in Education, New York

[6] ElSaheli-Elhage R (2021) Access to students and parents and levels of preparedness of educators during the COVID-19 emergency transition to e-learning. Int J Stud Educ 3(2):61-69

[7] Cevikbas M, Kaiser G (2020) Flipped classroom as a reform-oriented approach to teaching mathematics. Zdm 52(7):1291-1305

[8] Islam M, Barna S D, Raihan H, Khan M, Hossain M T (2020) Depression and anxiety among university students during the COVID-19 pandemic in Bangladesh: a web-based cross-sectional survey. PLoS ONE 15(8):e0238162

[9] Ardan M, Rahman F F, Geroda G B (2020) The influence of physical distance to student anxiety on COVID-19, Indonesia. J Crit Rev 7(17):1126-1132

[10] Berardi F. (2020) Crónica de la psicodeflación [Chronicle of psychodeflation]. In P Amadeo (Ed.), Sopa de Wuhan: pp. 35-54

[11] González-Calv G, Varea V, Martínez-Álvarez L (2020) 'I feel, therefore I am': Unpacking preservice physical education teachers' emotions. Sport, Education and Society 25 (5): 543-555

[12] Beck U (1992) Risk society: Towards a new modernity. Sage

[13] Agamben G (2020) La invención de una epidemia [The creation of an epidemic]. In P. Amadeo (Ed.), Sopa de Wuhan: pp. 17-19 